UCRL-JC-123066

PREPRINT

CONF-96068-1

\title{
An Approach for the Development of an Aerodynamic-Structural Interaction Numerical Simulation for Aeropropulsion Systems
}

J. Naziar

R. Couch

M. Davis

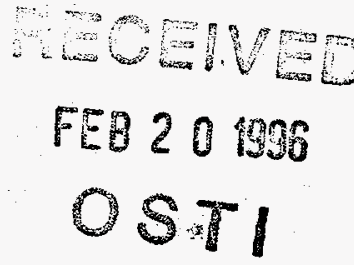

This paper was prepared for submittal to the 39th ASME International Aeroengine Conference and Congress

Birmingham, England

June 10-13, 1996

January 1996

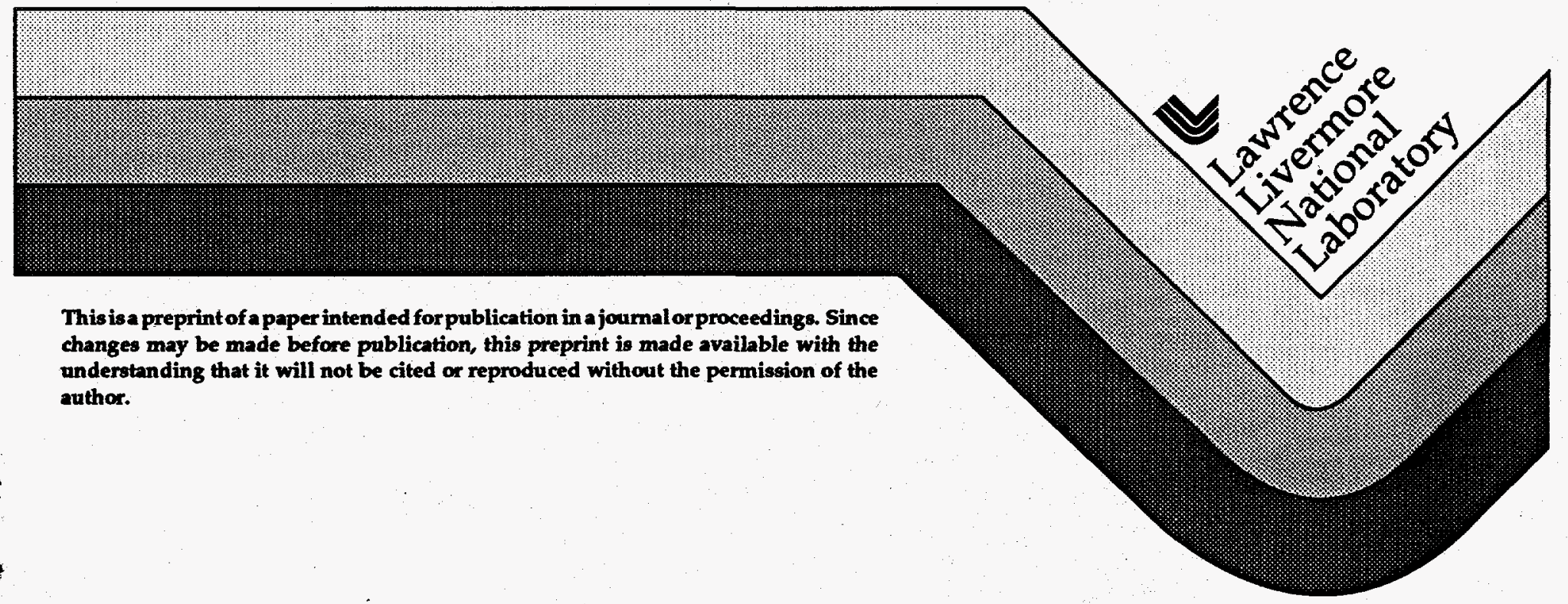




\section{DISCLAIMER}

This document was prepared as an account of work sponsored by an agency of the United States Government. Neither the United States Government nor the Uni versity of California nor any of their employees, makes any warranty, express or implied, or assumes any legal liability or responsibility for the accuracy, completeness, or usefulness of any information, apparatus, product, or process disclosed, or represents that its use would not infringe privately owned rights. Reference herein to any specificcommercial products, process, or service by trade name, trademark, manufacturer, or otherwise, does not necessarily constitute or imply its endorsement, recommendation, or favoring by the United States Government or the University of California. The views and opinions of authors expressed herein do not necessarily state or reflect those of the United States Government or the Lniversity of California, and shall not be used for advertising or product endorsement purposes. 


\section{AN APPROACH FOR THE DEVELOPMENT OF AN AERODYNAMIC-STRUCTURAL INTERACTION NUMERICAL SIMULATION FOR AEROPROPULSION SYSTEMS*}

\author{
Javaid Naziar \\ Boeing Commercial Airplane Group \\ Propulsion Research \\ Seattle, WA 98124
}

\author{
Rich Couch \\ Lawrence Livermore \\ National Laboratory \\ Livermore, CA 94550
}

\author{
Milt Davis \\ Sverdrup Technology, Inc. \\ Arnold Engineering Development Center \\ Arnold Air Force Base, TN 37389
}

\section{NOMENCLATURE}

\begin{abstract}
Traditionally, aeropropuision structural performance and aerodynamic performance have been designed separately and later mated together via flight testing. In today's atmosphere of declining resources, it is imperative that more productive ways of designing and verifying aeropropulsion performance and structural interaction be made available to the aerospace industry. One method of obtaining a more productive design and evaluation capability is through the use of numerical simulations. Currently, Lawrence Livermore National Laboratory has developed a generalized fhuid/structural interaction code known as ALE3D. This code is capable of characterizing fluid and structural interaction for components such as the combustor, fan/stators, inlet andior nozzles. This code solves the 3D Euler equations and has been applied to several aeropropulsion applications such as a supersonic inlet and a combustor rupture simulation. To characterize aerodynamicstructural interaction for rotating components such as the compressor, appropriate turbomachinery simulations would need to be implemented within the ALE3D structure. The Amold Engineering Development Center is currently developing a threedimensional compression system code known as TEACC (Turbine Engine Analysis Compressor Code). TEACC also solves the 3D Euler equations and is intended to simulate dynamic behavior such as inlet distortion, surge or rotating stall. The technology being developed within the TEACC effort provides the necessary turbomachinery simulation for implementation into ALE3D. This paper describes a methodology to combine three-dimensional aerodynamic turbomachinery technology into the existing aerodynamic-structural interaction simulation, ALE3D to obtain the desired aerodynamic and structural integrated simulation for an aeropropulsion system..
\end{abstract}

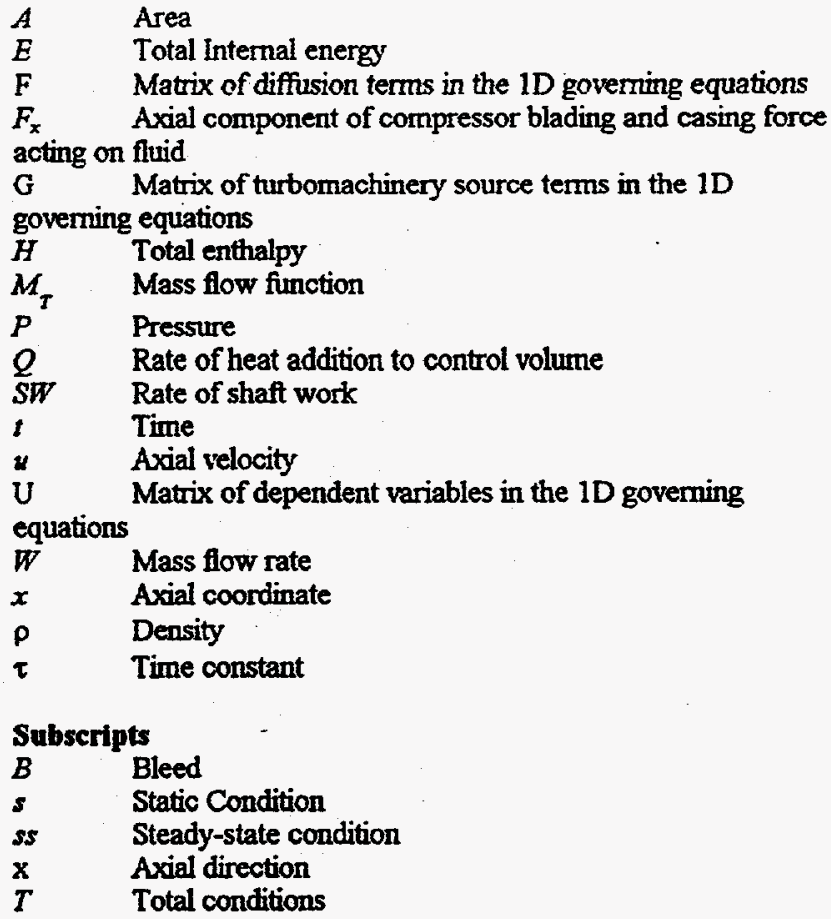

\section{INTRODUCTION}

A joint research and development activity is underway between the Boeing Commercial Airplane Group, Propulsion Research (BCAG),

\footnotetext{
- The work reported herein was performed under the auspices of the U.S. Department of Enerty by the Lawrence Livermore National Laboratory under contract No. W-7405-ENG-48 and by the Amold Engineering Development Center (AEDC). Air Force Materiel Command (AFMC). Work and analysis for this research by AEDC were done by personnel of Sverdrup Technology, Inc., AEDC Group, technical services contractor. Further reproduction is authorized to satisfy needs of the U. S. Governunent.
} 
the Lawrence Livermore National Laboratory (LLNL), and the Amold Engineering Development Center (AEDC). The goal of the activity is to address a variety of issues related to safety and failure, surge, and inlet fluctuations provide examples of the phenomena of interest.

Recent advances in turbornachinery design are leading to very high thrust, light weight commercial engines that challenge all fronts of technology development. Hight temperature super alloys with single crystal construction offer tremendous resilience in extremely harsh turbine engine operating environments. Sirnilarly, the high bypass wide chord light weight hollow or composite fan blade offers tremendous strength during bird strikes, hale ingestion, and surge cycles.

Engines in general are susceptible to premature failure if imperfections are generated either in the manufacturing process or through service-related damage. High thrust engines share the same susceptibility while producing highly energetic fragnents durung a failure event. Failures that can lead to high velocity fragnents can be a hazard to the aircraft and are a safety issue of considerable importance to the commercial aircraft industry.

In recent years attention has been focused on a series of events that affect the certification issue dealing with fan-blade-off containment. It is required by the Federal Aviation Agency (FAA) that the engine be able to contain a fan blade which has been released followed by a safe shutdown. This has been successfully demonstrated by all turbine engines flying today. However, with the larger engines being produced for the newest commercial transports, BCAG is concemed with the off-balance loads that are generated during the fan blade release and that are transferred to engine nacelle, thrust reverser, cowling engine mounts and other aircraft structures. During a fan-blade-off event, the failed blade transfers all its kinetic energy to the nacelle. This dissipation of energy generates force moments that are further compounded by asymmetric rubbing of the off-balance rotor with the cowling. These force moments are transmitted through the cowling to the aircraft structure.

Engine surge can accompany a fan blade off event. During surge, the flow direction through the core compressor up to the combustion chamber reverses. This flow reversal empties hot combustion gases from the combustor into the inlet until the purming characteristic dominates once again therefore shifting the flow direction once again. This process may repeat several times within a second violently shifting the flow direction. This induces tremendously violent dynamics on the engine which eventually propagate to the engine nacelle, cowling, thrust reverser, engine mounts, engine strut and the airplane. One can envision that these dynamics can perhaps add to the dynamics created by a fan-bladeoff scenario.

Engine surges can also be initiated by inlet distortion created by turbulence, wind shears or sorne other aircraft maneuvers. Regardless of the cause, engine surge produces the same type of violent dynamics as has been discussed above. Engine surges, in general are far more common in the field than the fan-blade-off event. Unlike the fan-blade-off event, where the engine must be shut down, an engine experiencing surge can recover and continue to operate safely, provided that the conditions initiating surge are performance of aircraft propulsion systems through numerical simulations. The focus is provided by the need to understand the interaction between structural and aerodynamic transients. Blade removed. Recent advances in engine control systems have provided good recoverability from this kind of event.

The major goal of the BCAG/LLNL/AEDC collaboration is to provide the capability to analytically predict engine surge flow distribution, thermal/structural dynamics, and dynarnic loads and stresses on a given installation configuration. Currently, the joint study focuses on a small scale wind tunnel model about to be tested at NASA for the High Speed Commercial Transport (HSCT) program as well as several high bypass commercial engines. In addition the feasibility of coupled non-linear thermal/fluid/stucturalengine transient dynamic modeling concepts will also be presented.

\section{TECHNICAL APPROACH}

The numerical simulation of engine surge cycles that would result from a fan blade-off event requires analytic methods that are coupled in terms of fluid, thermal, and structural interactions. Typically, these analyses are performed by analysts working in the individual disciplines using computational tools appropriate for that discipline. The incorporation of effects from other disciplines involves a partly phenomenological trial and enror iteration process. Usually a common solution can be arrived at via this process, but the procedure is time consuming and subject to error because of the cross talk between analysts whose expertise is limited to their own field. A more desirable approach would be to include all these effects in a consistent manner within a single simulation package. The goal of the collaboration between BCAG, LLNL and AEDC is to provide such a tool.

The joint research and development activity combines existing technology being developed at LLNL and AEDC. Each individual activity is briefly discussed and example application of the technology is presented to provide an overview of the capability of each technology. Finally, a proposal is outlined for the development of the desired end product and its envisioned applications.

\section{Engine Fluid/Thermal/Structural Interaction}

The development of 3D simulation tools at LLNL in the areas of structural, fluid and themal analysis has followed the traditional path of first developing capabitities limited to the particular topic of interest DYNA3D (Whirley and Engelmanr, 1993) is the culmination of two decades of research in structural analysis. TOPAZ3D (Shapiro, 1985) is the equivalent tool for use in thermal transport simulations. JOY (Couch, Albright, and Alexander, 1983), a 3D pure-Eulerian finite-difference code and CALE (Tipton, 1990), a 2D finite-difference arbitrary-Lagrangian-Eulerian code provide the heritage for the fluid mechanics capability that is being applied to the engine aero-structural analysis.

A 3D finite element code called ALE3D (Sharp et. al., 1995) has been developed as a means of merging many of the capabilities developed in the individual technology areas. ALE3D was developed from a version of DYNA3D. It uses the basic Lagrangian finite element techniques developed there but has not maintained an identical set of algorithrns as the two code efforts evolved along 
different paths. The treatment of solid elements, where fluid dynamics is treated, has been completely rewritten. The coding and the available models for treating beam and shell elements, however have been kept consistent with the equivalent DYNA3D models, although only a subset are currently available. Fluid mechanics and ALE techniques from JOY and CALE were modified for application to unstructured meshes and incorporated into ALE3D. Thermal and structural analysis techniques are generally developed first in DYNA3D and TOPAZ3D then migrated to ALE3D as required.

ALE3D is a finite element code that treats luid and elastic-plastic response on an unstructured grid. The grid may consist of arbitrarily connected hexahedral, shell and beam elements. The mesh can be constructed from disjoint blocks of elements which interact at the boundaries via slide surfaces or other types of boundary conditions. Nodes can be designated as relax nodes and ALE3D will adjust their position relative to the material in order to relieve distortion or to improve accuracy or efficiency. This relaxation process can allow nodes to cross material boundaries and create mixed or multi-material elements.

The basic computational step consists of a Lagrangian step followed by an advection, or remap step. This combination of operations is formally equivalent to an Eulerian solution while providing increased flexibility and in some cases, gieater accuracy. In the Lagrangian phase, nodal forces are accurnulated and an updated nodal acceleration is computed. Following DYNA3D (Hallquist, 1982), the stress gradients and strain rates are evaluated by a lowest order finite element method.

At the end of the Lagrangian phase of the cycle the velocities and nodal positions are updated. At this point several options are available. If the user wishes to run the code in a pure-lagrangian mode, no further action is taken and the code proceeds to the next time step. If a pure-Eulerian calculation is desired, the nodes are placed back in their original positions. This nodal motion or relaxation generates inter-element fluxes which must be used to update velocities, masses, energies, stresses and other constitutive properties. This re-mapping process is referred to as advection. Second-order-accurate schemes are required to perform this operation with sufficient accuracy. In addition, it is not generally adequate to allow advection only within material boundaries. ALE3D has the ability to treat multi-material elements, thus allowing relaxation to take place across material boundaries.

The full potential of the ALE approach is realized when the code user has options available to tailor the evolution of the mesh to maximize either efficiency or accuracy. In the simplest implementation the code is instructed to relax nodes as required to eliminate distortions in the mesh. A more powerful approach has the code relax nodes on the basis of an optimization scheme. To this purpose ALE3D utilizes a finite element based equipotential method developed by $R$. Tipton (Tipton, 1992). This method accommodates weighting functions which can be used to optimize the mesh based on some defined criterion. ALE3D currently allows weighting by pressure, by artificial viscosity, by plastic strain, by material number and along designated slip surfaces. The solution will result in a more highly resolved mesh in the volumes containing the highest weights. This provides a form of dynarnic mesh refinement. An illustration of this technique is presented in Figure 1 for a diffuser geometry.
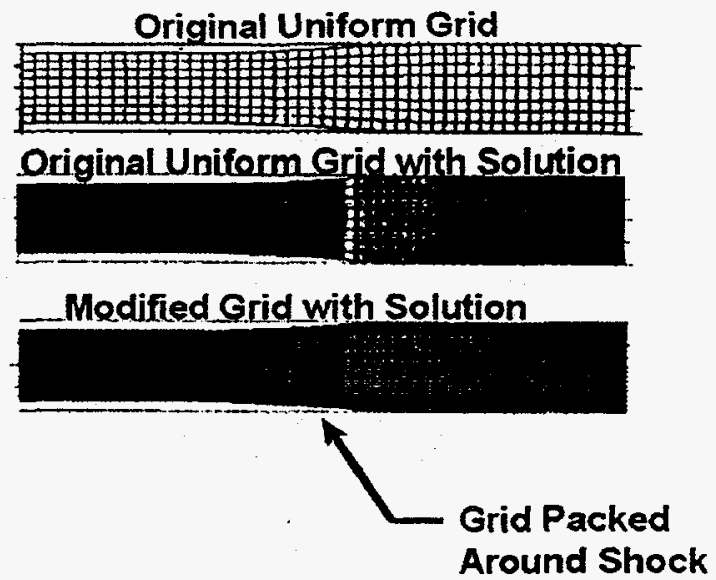

Figure 1. Grid Remapping Feature of ALE3D

This technique has proved useful in improving the effective resolution in shock tracking simulations. There are also a number of options available for selecting predetermined or dynamically progranmed mesh evolution in cases where that is appropriate.

A version of TOPAZ3D has been incorporated into ALE3D to provide a thermal transport capability. The TOPAZ3D package has been enhanced by the inclusion of a reaction chemistry module (Nichols and Westerberg, 1993). These capabilities are utilized in a split operator mode whereby the operator can be applied at a time interval that is appropriate for thermal effects and need not be consistent with the time step for the dynamics.

A critical step in any type of transient analysis for rotating turbomachinery is to stabilize the configuration to steady state conditions in terms of both structural and fluid dynamics. Often it is required to follow many revolutions of structural components without perturbation from numerical integration errors. This places severe constraints on the techniques used to integrate the dynamic equations through time.

Prestressing a body in DYNA3D is performed in a fully dynamic mode. The technique involves an initial phase where body forces are applied to the unstressed configuration. Centrifugal forces are applied to represent the effect of rotation. The oscillatory response of the structure to this non-equilibrium loading is controlled by applying a viscous damping term. Judicious application of this damping term allows an efficient relaxation to the equilibrium configuration. When the kinetic energy in the structure falls to a value deemed negigible, the code replaces the explicit centrifugal forces with an equivalent rotational velocity field and the code begins the actual time integration. Figure 2 depicts a rotating structure for which this process has been applied. This particular configuration represents the equilibrium state of the structure prior to blade release. This simulation is intended to be one phase in the computational sequence from blade release to surge to structural response. The von Mises stress in an element in a blade as it undergoes many revolutions was nearly constant for a full 100 revolutions. The stability of von Mises stress in an element is an indication of the accuracy of the numerical algorithms. 


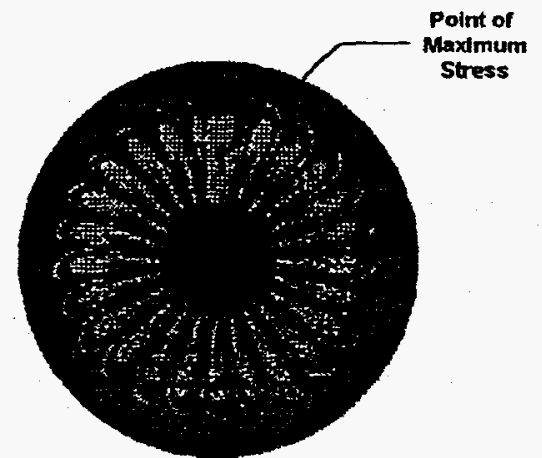

Figure 2 Single Fan Stage Structural Analysis Using DYNA3D

The analogous problem for fluid dynamics is exemplified with the geometry shown in Figure 3. The flat structure is a mock of wing component. This together with the nacelle and center-body model a test configuration of an engine inlet to be tested in a wind tunnel in association with the HSCT Program. Given flow boundary conditions in the far field and at the outlet of the inlet section, ALE3D must be able to settle to an equilibrium solution that is consistent with the actual flow field. The approach is merely to initialize the problem with the far field velocity pressure and density and let the dynamios proceed until equilibrium is reached. The efficiency of the relaxation process is sensitive to the choice for flow field within the nacelle, but generally, integrating for a few transit times is usually sufficient.

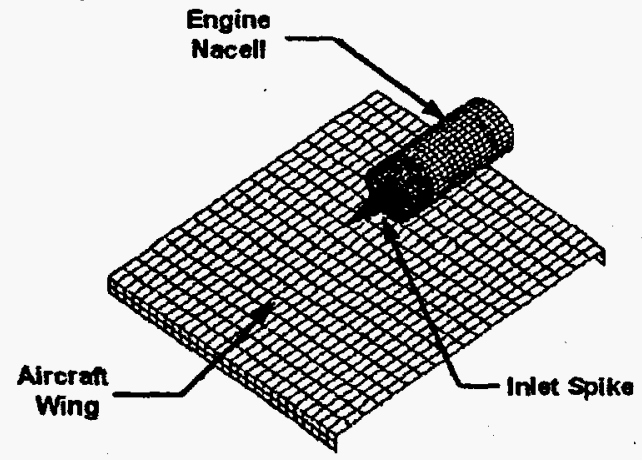

Figure 3. Grid Structure for Aerodynamic Analysis of an Inlet-Wing Combination

Figure 4 illustrates the degree of agreement between the ALE3D calculation and the actual pressure distribution within the nacelle.

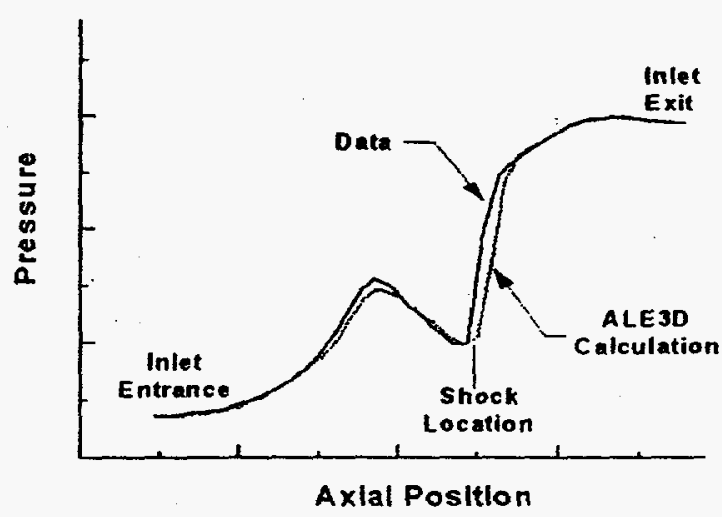

Figure 4. Comparison of ALE3D Pressure Calculations in a Supersonic Inlet to that Observed Experimentally

\section{Engine Surge Analysis Codes}

Fan-blade-off events can create failure in the compressor leading to engine surge. Normally the fan performs work on the incoming air such that air is purnped from low pressure at the inlet to a higher pressure at the outiet. This work ensures that the flow stays in the direction from compressor inlet to exit.

To model a fan-blade-off event both prior to and after the event analytically one can use a simulation that describes each blade and each stage exactly. The modeling of each blade in a discretized marmer can employ many elements which once replicated to represent all the stage of high compressor, turbine, nacelle, casing, thrust reverser and other engine components can create a model that is so huge that analysis would take too long to run. This limitation requires an alternative strategy to the modeling of the fanblade-off event other than discretizing and describing each blade and stage.

AEDC has been concemed with engine transient dynamics for over a decade and has been involved in testing various military engines. AEDC has accumulated a vast knowledge of engine transient dynamics and has applied that knowiedge to analytical procedures which they use to complement test results and perform "what if" investigations. The AEDC numerical codes incorporate Euler equations of fluid motions along with turbornachinery source terns to simulate turbine engine performance and operability. These analytical codes have been successfully adapted not only to military engines, but also to high by-pass commercial turbine engines.

DYNTECC (Hale and Davis, 1992) is a one-dimensional, stage-bystage, compression system mathematical model which is able to analyze any generic compression system. DYNTECC uses a finite difference numerical technique to simultaneously solve the mass, momentum, and energy equations with turbomachinery source terms (mass bleed, blade forces, heat transfer, and shaft work). The source terms are determined from a complete set of stage pressure and temperature characteristics provided by the user. 
Illustrated in Figure 5 is a representative, single-spool, multi-stage compressor and ducting system. The compressor and ducting system are modeled by an overall control volume. Acting on the fluid control volume is an axial-force distribution, $F_{x,}$ attributable to the effects of the compressor blading and the walls of the system. Appropriate inlet and outlet boundary conditions are applied at the inflow and outflow boundary locations. Energy supplied to the control volume includes the rate of heat added to the fluid, $Q$, and shaft work done on the fluid, $S W_{x}$. Mass transfer rates across boundaries other than the inlet or exit (such as the case of interstage bleeds) are represented by the distribution, $W_{B}$.
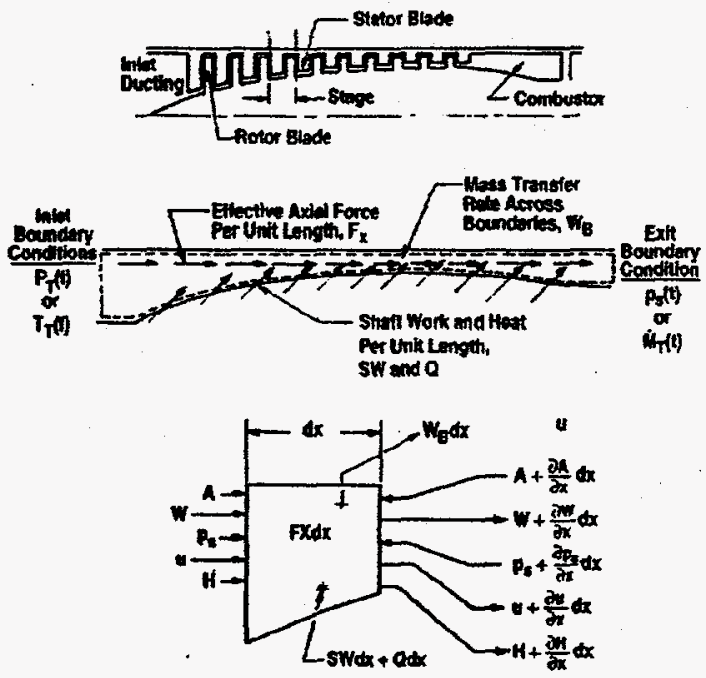

Figure 5. DYNTECC Control Volume Technique

The overall control volume is subdivided into a set of elemental control volumes. Typically, the compressor section is subdivided by stages either as rotor-stator or vice versa depending on the way experimental stage characteristics may have been obtained. All other duct control volumes are divided to ensure an appropriate frequency response. The goveming equations are derived from the application of mass, momentum, and energy conservation principles $\therefore$ to each elemental control volume. These equations can be expressed as:

$$
\frac{\partial U}{\partial t}+\frac{\partial F}{\partial x}=\mathbf{G}
$$

where:

$$
\mathbf{U}=\left\{\begin{array}{c}
\rho A \\
\rho A u \\
E A
\end{array}\right\} ; \mathbf{F}=\left\{\begin{array}{c}
\rho A u \\
\rho A u^{2}+P A \\
u(E A+P A)
\end{array}\right\} ; \mathbf{G}=\left\{\begin{array}{c}
-W_{B_{x}} \\
F_{x} \\
Q_{x}+S W_{x}-H_{B x}
\end{array}\right\}
$$

To provide stage force, $F_{x}$ and shaft work, $S F_{x}$ inputs to the momentum and energy equations, a set of quasi-steady stage characteristios must be available for closure. The stage characteristics provide the pressure and temperature rise across each stage as a function of steady airflow. Using pressure rise, temperature rise, and airflow, a calculation can be made for stage steady-state forces and shaft work. A typical set of stage characteristics is presented in Fig. 6.
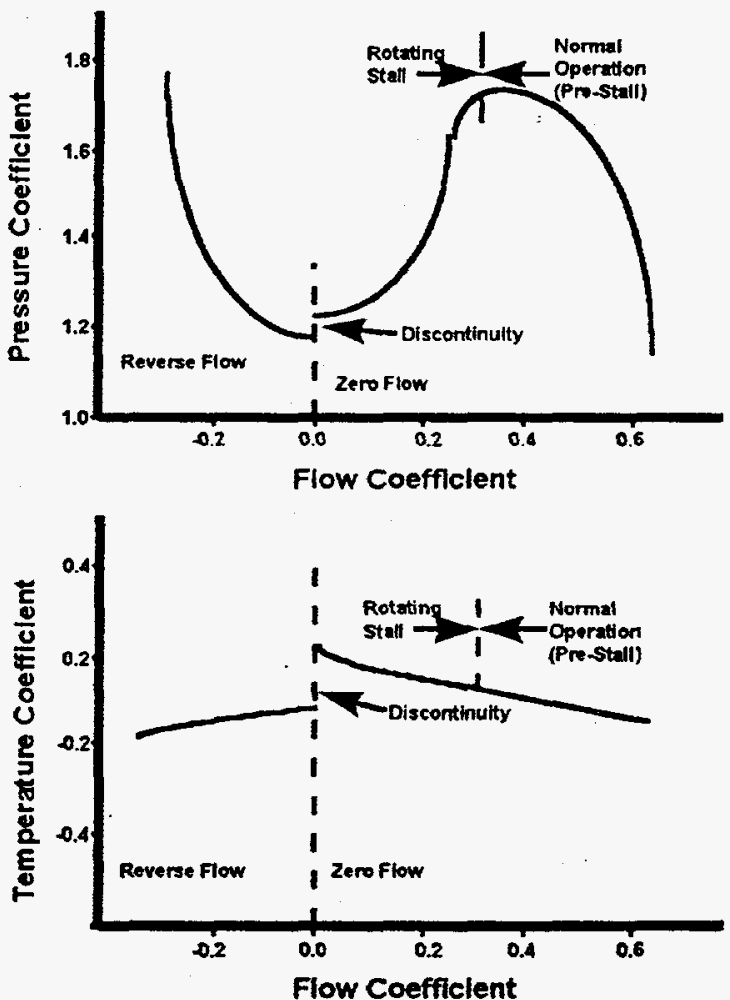

Figure 6. Typical Set of Stage Characteristics

The above discussion centers on the steady characteristic. During transition to surge and development of rotating stall, the steady stage forces derived from the steady characteristics are modified for dynamic behavior via a first-order lag equation of the form:

$$
\tau \frac{d\left(F_{X}\right)}{d t}+F_{X}=F_{X s s}
$$

The time constant, $\tau$, is used to calibrate the model to provide the correct post-stall behavior. The inflow boundary condition during normal forward flow is the specification of total pressure and temperature. The exit boundary condition is the specification of exit Mach number or static pressure. During reverse flow the inlet is converted to an exit boundary with the specification of the ambient static pressure. Therefore, both the inlet and exit boundary function as exit boundaries during a surge cycle.

Currently, AEDC is developing a three-dimensional version of DYNTECC known as TEACC (Turbine Engine Analysis Compressor Code), (Hale, et al 1994). The technology being developed within TEACC will ultimately be implemented into ALE3D providing a true 3D system surge/rotating stall capability. Details of TEACC can be found in the cited reference.

\section{SURGE CYCLE ANALYSIS}


To illustrate the surge cycle analysis that can be conducted with DYNTECC, Boeing analyzed the aerodynamic behavior of a present-day commercial high pressure compressor (HPC) undergoing surge. System geometry was configured to include the fan and combustor geometry that interacts with the compressor during surge. Stage characteristics were synthesized using a streamline curvature code for prestall characteristics while using experience from both low speed and high speed systems to estimate post-stall characteristics. The exit mach number was reduced at a rate simulating a combustor pressure pulse which initiates system surge.

A comparison of DYNTECC's prediction of aerodynamic behavior is presented Figure 7. The experimental pressure ratio presented represents component perfomance during surge of the HPC. DYNTECC reproduces that signature both in level and frequency. Since DYNTECC compares with the pressure ratio signature, the pressure at the inlet of the HPC is assumed to be sccurate as presented in Figure 8 . The pressure profile is what is required by the ALE3D code as a boundary condition. An additional application of DYNTECC and validation with experinental results can be found in the reference by Owen and Davis, 1994.

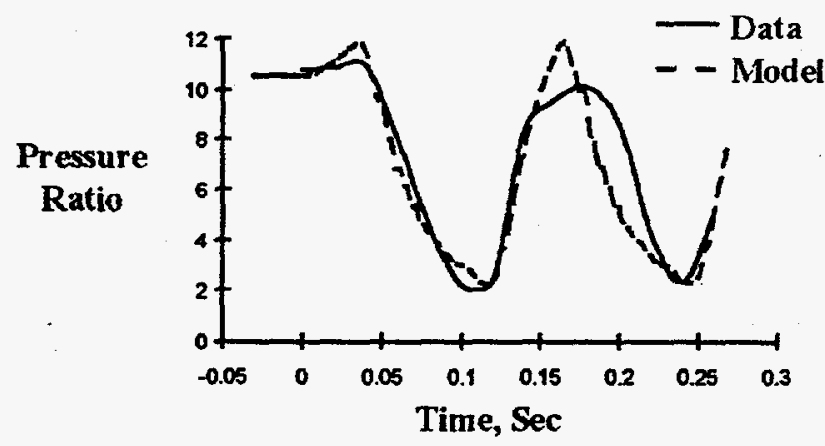

Figure 7. Comparison of Predicted Surge Frequency and Pressure Ratio to Experimental Results

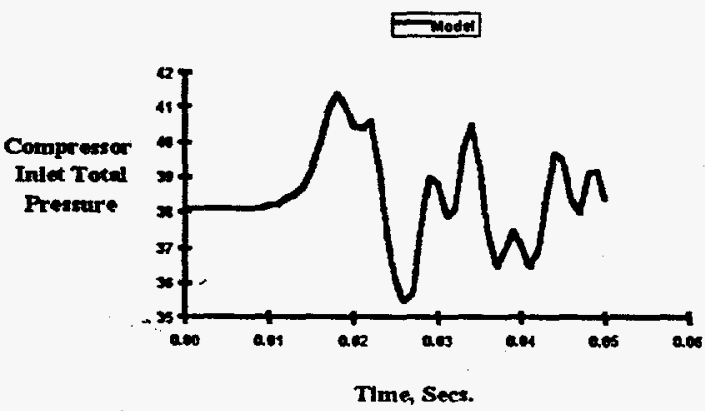

Figure 8 Model Predicted Compressor Inlet Total Pressure During Surge Event

\section{AERODYNAMIC - STRUCTURAL ANALYSIS}

An engine inlet configuration associated with the HSCT program that is scheduled for testing in 1996 has been analyzed. A scale mock-up of the desired HSCT engine inlet is to be tested during an inlet unstart and its transient loading on the simulated scaled wing panel is to be measured. In addition to the plume size, intensity and pattern of the shock waves that are generated during an inlet-unstart is to be monitored. Inlet start is a complex three dimensional phenomena where a supersonic flow which comes through the inlet is stabilized to some acceptable subsonic conditions before entering the fan. This produces a shock wave that sits strategically somewhere in the inlet thus creating a transition zone from supersenic flow to sub-sonic flow within the HSCT inlet. Pressure contours at equilibrium and at plume peak are illustrated in Figure 9.

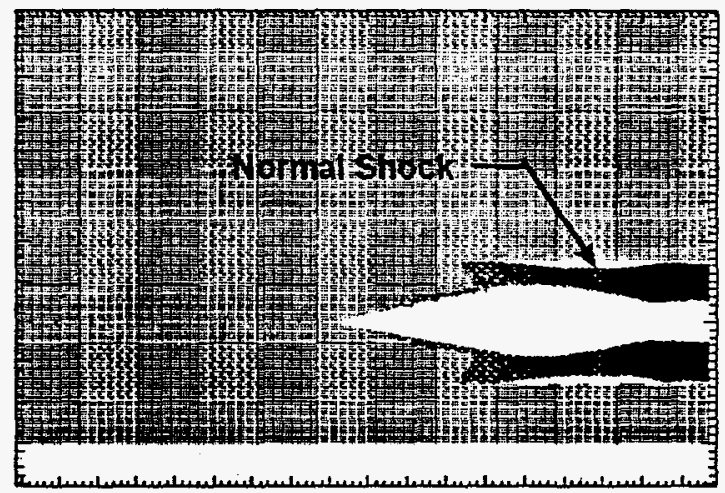

Figure 9. Pressure Contours at Equilibrium with Imbedded Normal Shock During Steady Operation

If for whatever reason the engine undergoes a transient such as an engine surge, the stable shock wave will be disnupted and become unstable possibly spilling out around the engine. This bubble'plume will spread and produce loading on the surrounding structure such as wing and can produce considerable challenge to the aircraft attitude control surfaces which will try to compensate for such puise loadings. In addition if the bubble/plume size is large enough it could be sucked in by the adjacent engine and thus pertaps causing it to unstart as well. This will obviously intensify the dynamics for the control system to compensate and thus requiring a thorough understanding of this phenomena.

The initial approach has been to analyze this coupled aerodynamicstructural interaction with a decoupled numerical techrique. The decoupled approach that was taken was to model the surge cycle frequencies and intensity using DYNTECC for a typical high pressure turbine engine and correlate it with the SR-71 supersonic engine's surge data. This scaled pressure loading at the fan face was then introduced as a boundary condition to ALE3D which characterized the HSCT inlet steady state shock location in a three dimensional inlet. The boundary condition imposed in ALE3D from DYNTECC did not incorporate radial and theta variations because of DYNTECC's one-dimensional formulation.

The appropriate boundary conditions were applied and the equilibrium flow was obtained as described in the previous section. The surge conditions were then applied as a time-varying onedimensional pressure boundary condition. The time dependent boundary condition is illustrated in Figure 10. The boundary 
condition captures the initial nature of the surge cycle as illustrated in Figure 8 . The initial spike and rapid drop-off occurs within the first 10 to 15 milliseconds after the event is initiated. The highly cyclic nature of the blowdown part of the cycle is not represented by the boundary condition. However, the inlet has already unstarted by that time and the cyclic oscillations no longer play a role in iniet unstart.

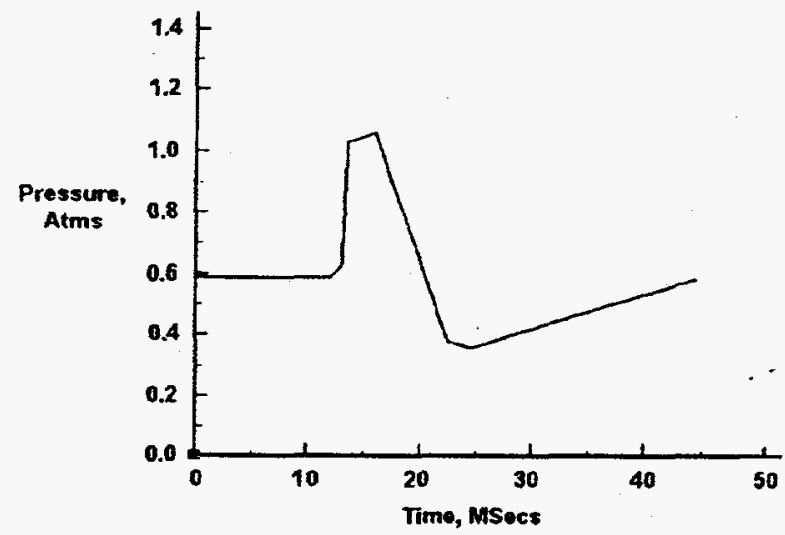

Figure 10. Surge Pressure Boundary Condition for Mock HSCT Inlet

The surge condition caused the shock to propagate out of the inlet with a finite plume size as illustrated in Figure 11. Figure 12 presents a plot of displacement on the wing-mock surface which indicates the dynamic response of the structure to the surge induced loading. The calculated results will be compared with data when the experimental results become available

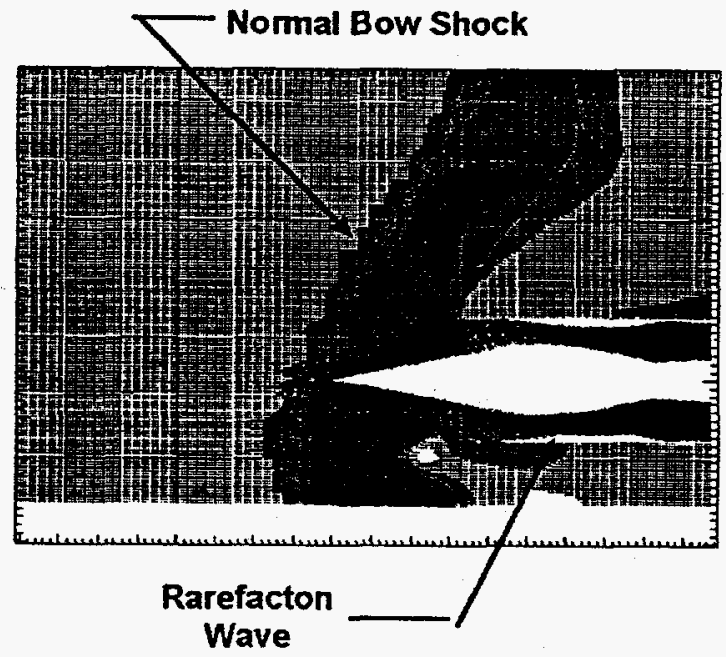

Figure 11. Inlet Unstart Due to Engine Surge Cycle

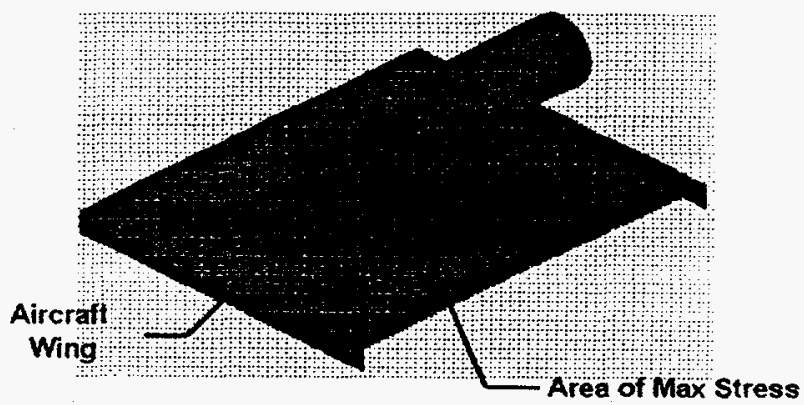

Figure 12. Effect of Inlet Unstart on Aircraft Wing Assembly

\section{PROPOSED APPROACH}

The objective of the joint effort between the Lawrence Livermore National Laboratory, the Amold Engineering Development Center, and the Boeing Commercial Airplane Group is to develop a general purpose aerodynamic-structural simulation for aircraft propulsion systems and their components with the capability to interact with aircraft extemal flow fields and structures. This objective can be met using the technologies described in the previous sections. The technical approach would marry the turbomachinery system level technology represented by the AEDC DYNTECC and TEACC codes into the LLNL ALE3D aerodynamic-structural simulation. A systern level approach is envisioned which would allow internal engine component and subcomponents (i.e. a compressor stage or blade row) to interact with the full turbine engine system and thus with external aircraft structures. If an analysis of an internal engine component was desired, a more traditional CFD - finite element approach would be available through zooming.

Envisioned applications include:

- Compressor-Inlet Operability Investigations

- Engine-Aircraft System Aerodynamic / Structural Analysis

- Effect of Aircraft Maneuvers on Engine Structures

- Nozzle Aft-Body Aeromechanical Interaction

- Turbomachinery Aeromechanical Analysis

- Acoustical Analysis and Effects of Resonant Acoustios on Structures

With this coupled approach, a new numerical tool will become available to the aeropropulsion community that will allow fully interactive analysis between the traditionally uncoupled aerodynamics and structural disciplines. By developing this tool with government resources, this tool will become nonproprietary and be available to all industry and government agencies.

\section{ACKNOWLEDGEMENTS}

The inlet geometry and flow analysis of the supersonic inlet was provided by Dr. Lanry T. Clark of the Boeing HSCT propulsion staff. The streamline curvature analysis was provided by Dr. R. M. Hearsey of the Boeing propulsion research staff. The authors gratefully acknowledge Dr. Clark's and Dr. Hearsey's contribution to this paper.

REFERENCES 
Couch, R. G., Albright, E., Alexarider, N., "JOY Computer Code," Lawrence Livermore National Laboratory, UCID-19688, 1983.

Hale, A. A., M. W. Davis, Jr., and K. R. Kneile, "Turbine Engine Analysis Compressor Code: TEACC - Part I: Technical Approach and Steady Results", AlAA Paper \# ALAA-94-0148, Presented at the 32nd Aerospace Sciences Meeting and Exhibit, Reno Nevada, January 1994.

Hale, A. A. and M. W. Davis, $J_{r}$., "DYNamic Turbine Engine Compressor Code: DYNTECC - Theory and Capabilities", AIAA Paper \# AlAA-92-3190, Presented at the 28th Joint Propulsion Conference and Exhibit, Nashville, TN, July 1992.

Hallquist, J. O., "Theoretical Manual for DYNA3D," Lawrence Livermore National Laboratory, UCID-19401, draft. 1982

Nichols, A. L. III, Westerberg, K. W., "Modification of a Thermal Transport Code to Include Chemistry with Thermally Controlled Kinetics," Numer. Heat Transfer, Part B, Vol 24, pp 489-509, 1993

Owen, A, K., and M. W. Davis, $\mathbf{J}_{r}$., "Modeling the Dynamic Behavior of an Axial-Centrifugal Compression System", AlAA Paper \# AIAA-94-2802, Presented at the 30th ALAA Joint Propulsion Conference and Exhibit, Indianapolis, IN. June 1994

Shapiro, A. B., “TOPAZ3D - A Three-Dimensional Finite Element Heat Transfer Code," Lawrence Livermore National Laboratory, UCID-20484, 1985.

Sharp, R, Anderson, S., Dube, E., Futral, S., Otero, I., "User's Manual for ALE3D," Lawrence Livermore National Laboratory, unpublished, 1995.

Tipton, R., "CALE User's Manual," Lawrence Livermore National Laboratory, unpublished, 1990.

Tipton, R., Lawrence Livermore National Laboratory, unpublished, 1992.

Whirley, R. G.,Engeimann, B. E., 1993, A Nonlinear, Explicit, "Three Dimensional Finite Element Code for Solid and Structural Mechanics - User Manual", Lawrence Livermore National Laboratory, UCRL-MA-107254 Rev 1. 
, 

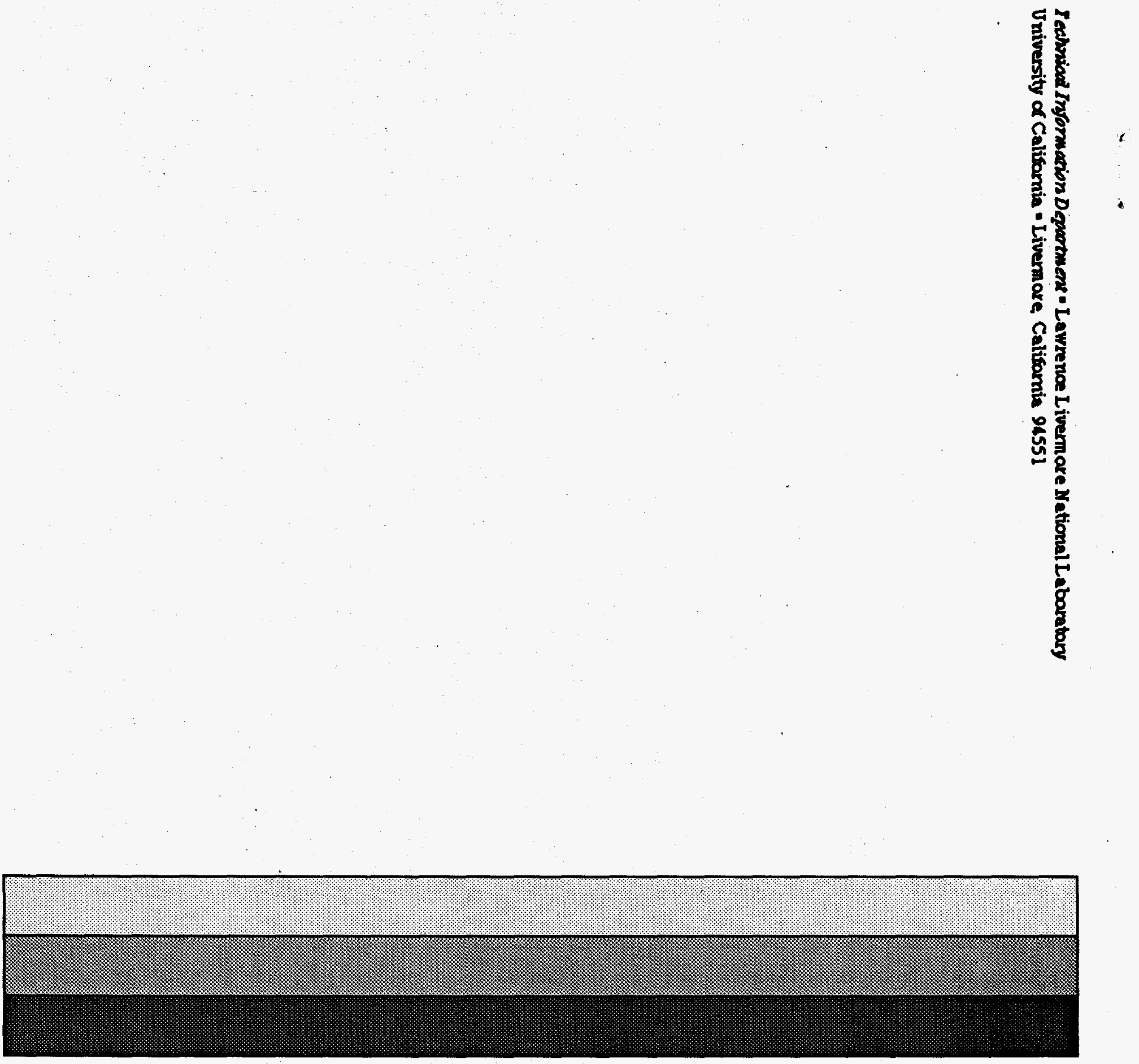


\section{AN APPROACH FOR THE DEVELOPMENT OF AN AERODYNAMIC-STRUCTURAL INTERACTION NUMERICAL SIMULATION FOR AEROPROPULSION SYSTEMS*}

\author{
Javaid Naziar \\ Boeing Commercial Airplane Group \\ Propulsion Research \\ Seattle, WA 98124
}

\author{
Rich Couch \\ Lawrence Livermore \\ National Laboratory \\ Livermore, CA 94550
}

\author{
Milt Davis \\ Sverdrup Technology, Inc. \\ Amold Engineering Development Center \\ Arnold Air Force Base, TN 37389
}

\section{NOMENCLATURE}

\section{ABSTRACT}

Traditionally, aerodynamic performance have been designed separately and later mated together via flight testing. In today's atmosphere of declining resources, it is imperative that more productive ways of designing and verifying aeropropulsion performance and structural interaction be made available to the aerospace industry. One method of obtaining a more productive design and evaluation capability is through the use of numerical simulations. Currently, Lawrence Livermore National Laboratory has developed a generalized fluid/structural interaction code known as ALE3D. This code is capable of characterizing fluid and structural interaction for components such as the combustor, fan/stators, inlet and/or nozzles. This code solves the 3D Euler equations and has been applied to several aeropropulsion applications such as a supersonic inlet and a combustor rupture simulation. To characterize aerodynamicstructural interaction for rotating components such as the compressor, appropriate turbomachinery simulations would need to be implemented within the ALE3D structure. The Amold Engineering Development Center is currently developing a threedimensional compression system code known as TEACC (Turbine Engine Analysis Compressor Code). TEACC also solves the 3D Euler equations and is intended to simulate dynamic behavior such as inlet distortion, surge or rotating stall. The technology being developed within the TEACC effort provides the necessary turbomachinery simulation for implementation into ALE3D. This paper describes a methodology to combine three-dimensional aerodynamic" turbomachinery technology into the existing aerodynamic-structural interaction simulation, ALE3D to obtain the desired aerodynamic and structural integrated simulation for an aeropropulsion system.

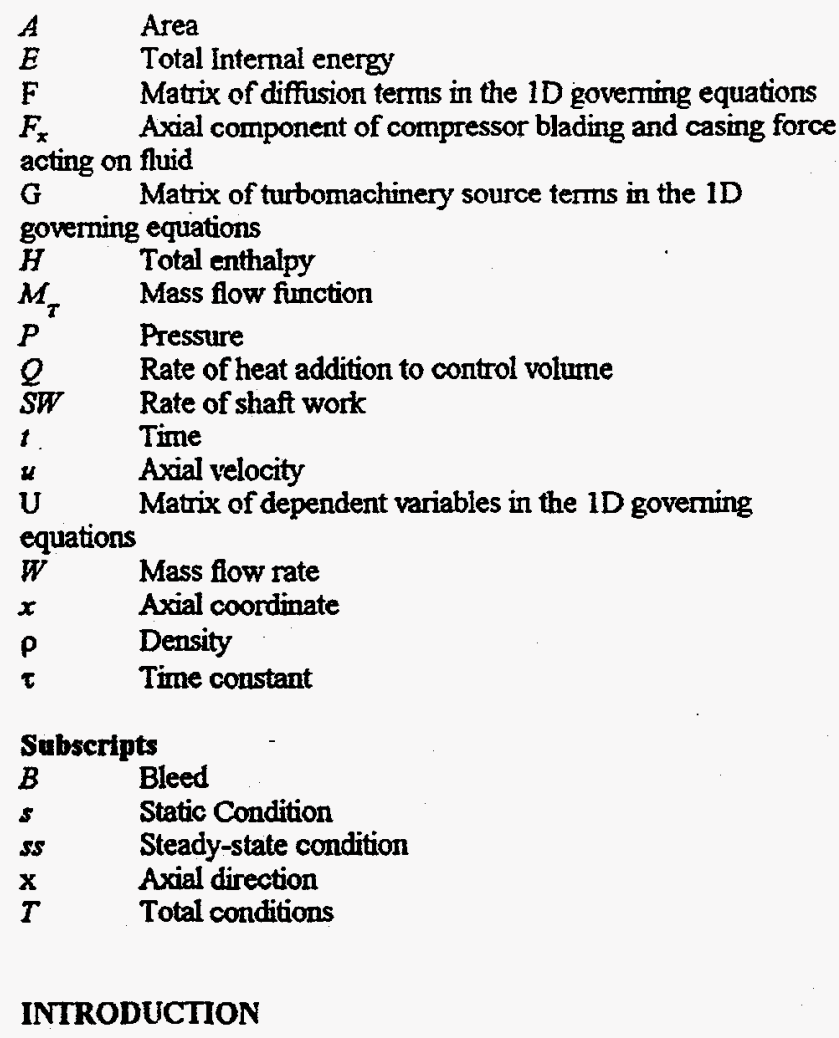

\section{INTRODUCTION}

A joint research and development activity is underway between the Boeing Cornmercial Aiplane Group, Propulsion Research (BCAG),

\footnotetext{
"The work reported herein was performed under the auspices of the U.S. Department of Enerty by the Lawrence Livermore National Laboratory under contract No. W-7405-ENG-48 and by the Amold Engineering Development Center (AEDC). Air Force Materiel Command (AFMC). Work and analysis for this research by AEDC were done by personelel of Svendrup Technology. Inc., AEDC Group, technical services contractor. Further reproduction is authorized to satisfy needs of the U. S. Govemunent.
} 
the Lawrence Livermore National Laboratory (LLNL), and the Amold Engineering Development Center (AEDC). The goal of the activity is to address a variety of issues related to safety and failure, surge, and inlet fluctuations provide examples of the phenomena of interest.

Recent advances in turbomachinery design are leading to very high thrust; light weight commercial engines that challenge all fronts of technology development. High temperature super alloys with single crystal construction offer tremendous resilience in extremely harsh turbine engine operating environments. Sirularly, the high bypass wide chord light weight hollow or composite fan blade offers tremendous strength during bird strikes, hale ingestion, and surge cycles.

Engines in general are susceptible to premature failure if imperfections are generated either in the manufacturing process or through service-related damage. High thrust engines share the same susceptibility while producing highly energetic fragments during a failure event. Failures that can lead to high velocity fragments can be a lazard to the aircraft and are a safety issue of considerable importance to the commercial aircraft industry.

In recent years attention has been focused on a series of events that affect the certification issue dealing with fan-blade-off containment. It is required by the Federal Aviation Agency (FAA) that the engine be able to contain a fan blade which has been released followed by a safe shutdown. This has been successfully demonstrated by all turbine engines flying today. However, with the larger engines being produced for the newest commercial transports, BCAG is concerned with the off-balance loads that are generated during the fan blade release and that are transferred to engine nacelle, thrust reverser, cowling engine mounts and other gircraft structures. During a fan-blade-off event, the failed blade transfers all its kinetic energy to the nacelle. This dissipation of energy generates force moments that are further compounded by asymmetric rubbing of the off-balance rotor with the cowiing. These force moments are transmitted through the cowling to the aircraft structure.

Engine surge can accompany a fan blade off event. During surge, the flow direction through the core compressor up to the combustion chamber reverses. This flow reversal empties hot combustion gases from the combustor into the inlet until the pumping characteristic dominates once again therefore shifting the flow direction once again. This process may repeat several times within a second, violently shifting the flow direction. This induces tremendously violent dynamics on the engine which eventually propagate to the engine nacelle, cowling thrust reverser, engine mounts, engine strut and the airplane. One can envision that these dynamics can perhaps add to the dynamics created by a fan-bladeoff scenario.

Engine surges can also be initiated by inlet distortion created by turbulence, wind shears or some other aircraft maneuvers. Regardless of the cause, engine surge produces the same type of violent dynamics as has been discussed above. Engine surges, in general are far more common in the field than the fan-blade-off event. Unilike the fan-blade-off event, where the engine must be shut down, an engine experiencing surge can recover and continue to operate safely, provided that the conditions initiating surge are performance of aircraft propulsion systerns through numerical simulations. The focus is provided by the need to understand the interaction between structural and aerodynamic transients. Blade removed. Recent advances in engine control systems have provided good recoverability from this kind of event.

The major goal of the BCAG/LLNL/AEDC collaboration is to provide the capability to analytically predict engine surge flow distribution, themalstructural dynamics, and dynanuic loads and stresses on a given installation configuration. Currently, the joint study focuses on a small scale wind turnel model about to be tested at NASA for the High Speed Commercial Transport (HSCT) program as well as several high bypass commercial engines. In addition the feasibility of coupled non-linear thernal/luid/structural/engine transient dynamic modeling concepts will also be presented.

\section{TECHNICAL APPROACH}

The numerical simulation of engine surge cycles that would result from a fan blade-off event requires analytic methods that are coupled in terns of fluid, thermal, and structural interactions. Typically, these analyses are performed by analysts working in the individual disciplines using computational tools appropriate for that discipline. The incorporation of effects from other disciplines involves a partly phenomenological trial and error iteration process. Usually a common solution can be antived at via this process, but the procedure is time consuming and subject to error because of the cross talk between analysts whose expertise is limited to their own field. A more desirable approach would be to include all these effects in a consistent manner within a single simulation package. The goal of the collaboration between BCAG, LLNL and AEDC is to provide such a tool.

The joint research and development activity combines existing technology being developed at LLNL and AEDC. Each individual activity is briefly discussed and example application of the technology is presented to provide an overview of the capability of each technology. Finally, a proposal is outlined for the development of the desired end product and its envisioned applications.

\section{Engine Fluid/Thermal/Structural Interaction}

The development of 3D simulation tools at LLNL in the areas of structural, fluid and thermal analysis has followed the traditional path of first developing capabilities limited to the particular topic of interest. DYNA3D (Whirley and Engelmann, 1993) is the culmination of two decades of research in structural analysis. TOPAZ3D (Shapiro, 1985) is the equivalent tool for use in themal transport simulations. JOY (Couch, Albright, and Alexander, 1983), a 3D pure-Eulerian finite-difference code and CALE (Tipton, 1990), a 2D finite-difference arbitrary-Lagrangian-Eulerian code provide the heritage for the fluid mechanics capability that is being applied to the engine aero-structural analysis.

A 3D finite element code called ALE3D (Sharp et. al., 1995) has been developed as a means of merging many of the capabilities developed in the individual technology areas. ALE3D was developed from a version of DYNA3D. It uses the basic Lagrangian finite element techniques developed there but has not maintained an identical set of algorithms as the two code efforts evolved along 